\title{
Cesarean Delivery Impacts Infant Brain Development
}

\author{
(DS.C. Deoni, (1)S.H. Adams, (D)X. Li, (D)T.M. Badger, (D)R.T. Pivik, (DC.M. Glasier, (DR.H. Ramakrishnaiah, (D)A.C. Rowell, and (D)X. Ou \\ O- $=$
}

\begin{abstract}
BACKGROUND AND PURPOSE: The cesarean delivery rate has increased globally in the past few decades. Neurodevelopmental outcomes associated with cesarean delivery are still unclear. This study investigated whether cesarean delivery has any effect on the brain development of offspring.
\end{abstract}

MATERIALS AND METHODS: A total of 306 healthy children were studied retrospectively. We included 3 cohorts: 2-week-old neonates (cohort 1, $n=32 / 11$ for vaginal delivery/cesarean delivery) and 8-year-old children (cohort 2, $n=37 / 23$ for vaginal delivery/cesarean delivery) studied at Arkansas Children's Hospital, and a longitudinal cohort of 3-month to 5-year-old children (cohort 3, $n=164 / 39$ for vaginal delivery/cesarean delivery) studied independently at Brown University. Diffusion tensor imaging, myelin water fraction imaging, voxel-based morphometry, and/or resting-state fMRI data were analyzed to evaluate white matter integrity, myelination, gray matter volume, and/or functional connectivity, respectively.

RESULTS: While not all MR imaging techniques were shared across the institutions/cohorts, post hoc analyses showed similar results of potential effects of cesarean delivery. The cesarean delivery group in cohort 1 showed significantly lower white matter development in widespread brain regions and significantly lower functional connectivity in the brain default mode network, controlled for a number of potential confounders. No group differences were found in cohort 2 in white matter integrity or gray matter volume. Cohort 3 had significantly different trajectories of white matter myelination between groups, with those born by cesarean delivery having reduced myelin in infancy but normalizing with age.

CONCLUSIONS: Cesarean delivery may influence infant brain development. The impact may be transient because similar effects were not observed in older children. Further prospective and longitudinal studies may be needed to confirm these novel findings.

ABBREVIATIONS: $\mathrm{BMI}=$ body mass index; $\mathrm{DMN}=$ default mode network; FA = fractional anisotropy; ICA = independent component analysis; IQ = intelligence quotient; MWF = myelin water fraction; RS-fMRI = resting-state fMRI; TFCE = threshold-free cluster enhancement; TBSS = Tract-Based Spatial Statistics; VBM = voxel-based morphometry

esarean delivery has become increasingly prevalent throughout the world. ${ }^{1}$ In the United States, about one-third of all births are by cesarean delivery, ${ }^{2}$ a $60 \%$ increase from the rate in

Received July 24, 2018; accepted after revision October 6.

From the Arkansas Children's Nutrition Center (S.H.A., T.M.B., R.T.P., X.O.), Little Rock, Arkansas; Departments of Radiology (X.L., C.M.G., R.H.R., A.C.R., X.O.) and Pediatrics (S.H.A., T.M.B., R.T.P., C.M.G., X.O.), University of Arkansas for Medical Sciences, Little Rock, Arkansas; Arkansas Children's Research Institute (C.M.G., R.H.R., A.C.R., X.O.), Little Rock, Arkansas; and School of Engineering (S.C.D.), Brown University, Providence, Rhode Island.

The studies were supported, in part, by the US Department of Agriculture-Agricultural Research Service Project (6026-51000-010-05S) at the Arkansas Children's Nutrition Center, the Marion B. Lyon Award at the Arkansas Children's Research Institute, and grants from the National Institute of Mental Health (R01MH087510) and the Bill and Melinda Gates Foundation. Dr Xiawei Ou is also supported by National Institutes of Health Centers of Biomedical Research Excellence grants P20GM121293 (Center for Translational Pediatric Research at Arkansas Children's Research Institute) and P30GM110702 (Center for Translational Neuroscience at University of Arkansas for Medical Sciences).
1996. ${ }^{3}$ Elective cesarean delivery without a medical indication is not uncommon ${ }^{4,5}$ and contributed to a considerable percentage $(8 \%)$ of the increase of cesarean deliveries in recent years. ${ }^{6}$ In addition, the large range of cesarean delivery rates across hospitals $^{7}$ suggests that practice variation, a modifiable factor, also played an important role in the increased prevalence of cesarean delivery. The World Health Organization recently reassessed available evidence and concluded that cesarean delivery should ideally be undertaken only when medically necessary, acknowledging that the relationship between the cesarean delivery rate and pediatric outcome is unclear. ${ }^{1}$ An important aspect to con-

Please address correspondence to Xiawei Ou, PhD, One Children's Way, Slot 105, Little Rock, AR 72202; e-mail: ouxiawei@uams.edu

-- Indicates open access to non-subscribers at www.ajnr.org

三 Indicates article with supplemental on-line appendix.

http://dx.doi.org/10.3174/ajnr.A5887 
Table 1: Study population demographics for cohort 1-two-week-old neonates $(n=43)$

\begin{tabular}{|c|c|c|c|}
\hline & $\begin{array}{l}\text { Vaginal Delivery } \\
(\text { Mean } \pm \text { SD) } \\
(n=32)\end{array}$ & $\begin{array}{l}\text { Cesarean Delivery } \\
\text { (Mean } \pm \text { SD) } \\
(n=11)\end{array}$ & $\begin{array}{c}P \\
\text { Value }\end{array}$ \\
\hline DTI TBSS study $(n=43)$ & 32 & 11 & \\
\hline RS-fMRI study $(n=37)$ & 27 & 10 & \\
\hline \multirow[t]{2}{*}{ Mother's age at delivery (yr) } & $29.0 \pm 3.9$ & $30.6 \pm 4.4$ & .26 \\
\hline & $29.2 \pm 4.1$ & $30.6 \pm 4.6$ & .35 \\
\hline \multirow[t]{2}{*}{ Mother's body fat $\%$ at early/prepregnancy } & $33.4 \pm 8.6$ & $36.9 \pm 8.5$ & .24 \\
\hline & $34.5 \pm 8.8$ & $38.4 \pm 7.3$ & .23 \\
\hline \multirow[t]{2}{*}{ Mother's BMI at 12 wk of pregnancy } & $25.1 \pm 5.2$ & $28.8 \pm 5.1$ & .04 \\
\hline & $25.5 \pm 5.5$ & $29.2 \pm 5.1$ & .08 \\
\hline \multirow[t]{2}{*}{ Mother's gestational weight gain (kg) } & $11.79 \pm 3.07$ & $9.02 \pm 3.37$ & $.02^{c}$ \\
\hline & $11.51 \pm 2.75$ & $8.87 \pm 3.51$ & $.03^{c}$ \\
\hline \multirow[t]{2}{*}{ Mother's IQ ${ }^{a}$} & $107.7 \pm 9.6$ & $104.2 \pm 6.9$ & .18 \\
\hline & $108.6 \pm 9.2$ & $104.8 \pm 6.9$ & .22 \\
\hline \multirow[t]{2}{*}{ Gestational age at MRI ${ }^{\mathrm{b}}$ (days) } & $290 \pm 6$ & $287 \pm 6$ & .20 \\
\hline & $291 \pm 6$ & $288 \pm 5$ & .22 \\
\hline \multirow[t]{2}{*}{$\operatorname{Sex}(M / F)$} & $20 / 12$ & $3 / 8$ & $.04^{\mathrm{c}}$ \\
\hline & $19 / 8$ & $3 / 7$ & $.03^{\mathrm{c}}$ \\
\hline \multirow[t]{2}{*}{ Birth weight $(\mathrm{kg})$} & $3.51 \pm 0.46$ & $3.56 \pm 0.54$ & .79 \\
\hline & $3.49 \pm 0.36$ & $3.63 \pm 0.52$ & .35 \\
\hline \multirow[t]{2}{*}{ Birth length $(\mathrm{cm})$} & $51.1 \pm 2.6$ & $49.3 \pm 2.6$ & $.05^{\mathrm{c}}$ \\
\hline & $51.2 \pm 2.1$ & $49.3 \pm 2.7$ & $.02^{c}$ \\
\hline \multirow{2}{*}{ Head circumference $(\mathrm{cm})$} & $36.2 \pm 1.1$ & $35.9 \pm 0.5$ & .22 \\
\hline & $36.3 \pm 0.9$ & $35.9 \pm 0.6$ & .31 \\
\hline \multirow[t]{2}{*}{ Diet for the first $2 \mathrm{wk}$ (breastmilk/formula) } & $29 / 3$ & $10 / 1$ & .98 \\
\hline & $24 / 3$ & $9 / 1$ & .92 \\
\hline
\end{tabular}

For each cell in the table, the first row is for the DTI TBSS study, the second row is for the RS-fMRI study

${ }^{\text {a }}$ Not available for 1 subject with vaginal delivery.

${ }^{b}$ Defined as gestational age at birth plus postnatal age at MRI.

c Consistently different between groups for both TBSS and RF-fMRI and therefore included as a covariate in the analysis.

sider is long-term neurodevelopment of children born by cesarean delivery. While some studies have not shown significant differences in intelligence quotient (IQ) between children born by cesarean delivery compared with vaginal delivery, ${ }^{8,9}$ others have suggested an increased risk of autism spectrum disorder and/or attention deficit/hyperactivity disorder associated with cesarean delivery, ${ }^{10-13}$ though it is unlikely that cesarean delivery is the single or main cause of these outcomes. ${ }^{14,15}$

The mixed and inconclusive associations between delivery mode and neurodevelopment may be partly attributed to numerous confounding factors that come into play during childhood (eg, diet and life-style, family environment and enrichment, and so forth), which may be avoided by evaluating the effects of cesarean delivery during early infancy. While neurobehavioral assessments in young infants are often not sufficiently sensitive for detecting small differences or for predicting long-term neurodevelopmental outcomes in the healthy population, quantitative neuroimaging by MR imaging can provide a comprehensive evaluation of the developing brain and reveal subtle changes. ${ }^{16-18}$ Examples of using several advanced MR imaging methods to reveal minor changes in infant brain development are given in On-line Appendix.

To test whether cesarean delivery has significant effects on infant brain development and whether these effects persist into and throughout childhood, we analyzed advanced brain MR imaging data in 3 cohorts of healthy children - cohort 1: two-week-old neonates with well-documented pregnancy and infant perinatal profiles; cohort 2: eight-year-old children who had undergone a suite of neuropsychological tests; and cohort 3: three-month to 5-year-old chil- dren with MR imaging data acquired and independently analyzed at a separate institution.

\section{MATERIALS AND METHODS}

All study procedures were approved by the local institutional review boards at the University of Arkansas for Medical Sciences (cohorts 1 and 2) and Brown University (cohort 3). Written informed consent was obtained from all parents or legal guardians of the study subjects.

\section{Study Population}

Cohort 1 consisted of 2-week-old, fullterm, healthy neonates ( $n=43,32 / 11$ for vaginal and cesarean delivery, respectively) from uncomplicated pregnancies. They were scanned at the Radiology Department of Arkansas Children's Hospital at $\sim 2$ weeks of age. The scan included regular imaging to screen for apparent brain abnormalities and diffusion tensor imaging and resting-state functional MR imaging (RSfMRI) to quantitatively evaluate brain structural and functional connectivity. In total, 43 infants (32/11 for vaginal and cesarean delivery, respectively) had valid DTI data and 37 infants (27/10 for vaginal and cesarean delivery, respectively) had valid RS-fMRI data and were included in the analysis. Their demographic information is presented in Table 1.

Cohort 2 consisted of healthy 7.5- to 8.5-year-old children ( $n=$ $60,37 / 23$ for vaginal and cesarean delivery, respectively). MR imaging examinations at Arkansas Children's Hospital included DTI evaluation of brain white matter and T1-weighted high-resolution structural images for voxel-based morphometry (VBM) evaluation of brain gray matter volume. Demographic information for subjects with valid DTI ( $n=35 / 21$ for vaginal and cesarean delivery, respectively) and VBM data ( $n=36 / 21$ for vaginal and cesarean delivery, respectively) is presented in Table 2.

Cohort 3 consisted of healthy, typically developing, 3- to 60month-old children $(n=203,164 / 39$ for vaginal and cesarean delivery, respectively). All subjects had at least 1 brain MR imaging at the Advanced Baby Imaging Lab at Brown University with valid myelin water fraction (MWF) imaging data. In total, 482 (377/105 for vaginal and cesarean delivery, respectively) datasets were acquired. Demographic information for this cohort is listed in Table 3.

Details such as inclusion/exclusion or selection criteria for these 3 cohorts and methods for demographic data measurements are presented in On-line Appendix.

\section{MR Imaging Data Acquisition and Analysis}

The data acquisition and analysis were based on established protocols at Arkansas Children's Hospital and Brown University and were similar to those in previous publications. ${ }^{16-23}$ Details are provided in On-line Appendix. 


\begin{tabular}{|c|c|c|c|}
\hline & Vaginal Delivery $(n=37)$ & Cesarean Delivery $(n=23)$ & $P$ Value \\
\hline DTI TBSS study $(n=56)$ & 35 & 21 & \\
\hline VBM study $(n=57)$ & 36 & 21 & \\
\hline \multirow[t]{2}{*}{ Birth weight (mean $\pm \mathrm{SD})(\mathrm{kg})$} & $3.37 \pm 0.40$ & $3.44 \pm 0.49$ & .79 \\
\hline & $3.34 \pm 0.43$ & $3.45 \pm 0.48$ & .55 \\
\hline \multirow[t]{2}{*}{ Gestational age at birth (mean \pm SD) (days) } & $276 \pm 9$ & $275 \pm 9$ & .43 \\
\hline & $275 \pm 10$ & $274 \pm 10$ & .75 \\
\hline \multirow[t]{2}{*}{ Age at MRI (mean $\pm \mathrm{SD})(\mathrm{yr})$} & $7.93 \pm 0.26$ & $7.87 \pm 0.24$ & .42 \\
\hline & $7.94 \pm 0.26$ & $7.92 \pm 0.27$ & .94 \\
\hline \multirow[t]{2}{*}{$\operatorname{Sex}(M / F)$} & $13 / 22$ & $11 / 10$ & .26 \\
\hline & $14 / 22$ & $9 / 12$ & .77 \\
\hline \multirow[t]{2}{*}{ Infant diet (breastmilk/formula) } & $14 / 21$ & $4 / 17$ & .10 \\
\hline & $15 / 21$ & $4 / 17$ & .08 \\
\hline \multirow[t]{2}{*}{$\mathrm{BMI}($ mean $\pm \mathrm{SD})$} & $16.8 \pm 2.9$ & $17.1 \pm 2.3$ & .49 \\
\hline & $16.7 \pm 2.9$ & $17.4 \pm 2.8$ & .27 \\
\hline SES ${ }^{a}$ mother's education: high school/college/graduate degree & $4 / 15 / 8$ & $2 / 5 / 3$ & .99 \\
\hline $\mathrm{SES}^{\mathrm{a}}$ father's education: high school/college/graduate degree & $7 / 17 / 3$ & $3 / 6 / 1$ & .99 \\
\hline $\mathrm{SES}^{\mathrm{a}}$ mother's annual income: NA/ $<\$ 20 \mathrm{k} / \$ 20 \mathrm{k}-\$ 50 \mathrm{k} />\$ 50 \mathrm{k}$ & $12 / 5 / 9 / 1$ & $1 / 2 / 3 / 4$ & .03 \\
\hline $\mathrm{SES}^{\mathrm{a}}$ father's annual income: NA/ $<\$ 20 \mathrm{k} / \$ 20 \mathrm{k}-\$ 50 \mathrm{k} />\$ 50 \mathrm{k}$ & $1 / 0 / 11 / 15$ & $0 / 0 / 3 / 7$ & .79 \\
\hline \multirow[t]{2}{*}{$\mathrm{IQ}(\mathrm{mean} \pm \mathrm{SD})$} & $110 \pm 10$ & $112 \pm 17$ & .53 \\
\hline & $112 \pm 11$ & $112 \pm 16$ & .72 \\
\hline \multirow[t]{2}{*}{ CELF-4 language scores (mean $\pm \mathrm{SD})^{\mathrm{b}}$} & $103 \pm 14$ & $104 \pm 16$ & .31 \\
\hline & $103 \pm 12$ & $105 \pm 14$ & .24 \\
\hline \multirow[t]{2}{*}{ CMS general memory index $(\text { mean } \pm S D)^{b}$} & $113 \pm 12$ & $109 \pm 13$ & .14 \\
\hline & $115 \pm 11$ & $111 \pm 13$ & .24 \\
\hline
\end{tabular}

Note:-SES indicates socioeconomic status; CELF-4, Clinical Evaluation of Language Fundamentals; CMS, Childhood Memory Scale; NA, not applicable. For each cell in the table, the first row is for the DTI TBSS study, the second row is for the VBM study.

a Only partial socioeconomic status data were available for all subjects ( $n=27$ for vaginal delivery, $n=10$ for cesarean delivery).

${ }^{\mathrm{b}}$ Not available for 1 subject with cesarean delivery.

Table 3: Study population demographics for cohort 3three-month- to 5-year-olds ( $n=203)$

\begin{tabular}{lccc}
\hline & $\begin{array}{c}\text { Vaginal } \\
\text { Delivery } \\
\text { (Mean } \pm \text { SD) }\end{array}$ & $\begin{array}{c}\text { Cesarean } \\
\text { Delivery } \\
\text { (Mean } \pm \text { SD) }\end{array}$ & $\begin{array}{c}\boldsymbol{P} \\
\text { Value }\end{array}$ \\
\hline MWF study $(n=203)$ & 164 & 39 & \\
Mother's post-secondary & $5.8 \pm 1.0$ & $6.0 \pm 0.9$ & .22 \\
$\quad$ education (yr) & & & \\
Mother's age at pregnancy (yr) & $29.0 \pm 5.6$ & $33.8 \pm 5.1$ & $<.001$ \\
Sex (M/F) & $93 / 71$ & $23 / 16$ & .86 \\
Gestational age at birth (days) & $277 \pm 8$ & $273 \pm 4$ & .001 \\
Birth weight (kg) & $3.54 \pm 0.45$ & $3.37 \pm 0.48$ & .06 \\
Birth length (cm) & $50.8 \pm 4.1$ & $50.8 \pm 4.1$ & .63 \\
No. of scans & $2.2 \pm 1.2$ & $2.4 \pm 1.3$ & .32 \\
Mean interscan period (days) & $296 \pm 144$ & $333 \pm 147$ & .12 \\
\hline
\end{tabular}

\section{Statistics}

For the comparison of demographic/anthropometric/neuropsychological data between delivery mode groups in cohorts 1 and 2, Wilcoxon rank sum tests were used for numeric parameters and Fisher exact tests (or $\chi^{2}$ tests) were used for categoric variables. For the voxelwise comparison of DTI parameters in Tract-Based Spatial Statistics (TBSS; http://fsl.fmrib.ox.ac.uk/ fsl/fslwiki/TBSS) analysis and RS-fMRI parameters in dualregression analysis, randomization with 5000 permutations was used with the threshold-free cluster enhancement (TFCE) option (testing of larger amounts of permutations did not change the results). To correct for multiple comparisons for the voxelwise analysis, we compared the observed TFCE image with the empiric null distribution computed across permutations of the maximum voxel-specific TFCE scores. ${ }^{24,25} P<.05$ corrected for multiple comparisons (voxelwise) was regarded as significant.
Because multiple independent component analysis (ICA) components were defined as meaningful functional networks and were fed into the dual-regression program for group comparison in the RS-fMRI analyses, an additional threshold of cluster sizes of $>5$ imaging voxels was used. For post hoc ROI analyses of DTI and RS-fMRI parameters, independent $t$ tests were used after confirming normal distribution of data and testing for equality of variance, and general linear model univariate analyses were used to compare differences, with covariates controlled. For the VBM analyses of regional gray matter volume, 2-sample $t$ tests with unequal variance were performed with multiple-comparison correction to control for family-wise error. $P<.05$ family-wise error-corrected was regarded as significant. For cohort 3, the Gompertz function parameters for the MWF curve of the 6 regions were compared between delivery groups using nonparametric tests, with significance defined as $P<.001$.

Potential confounders were controlled as covariates in statistical analyses. Specifically, for cohort 1, the TBSS and RS-fMRI dual-regression analyses were performed, respectively, when there were no potential confounders added as covariates; when adding demographic parameters that were consistently different between groups $(P \leq .05$ for both the TBSS and the RS-fMRI subsets) as covariates (gestational weight gain, infant sex, and birth length); and when adding an additional 2 parameters that were known potential confounders identified by our previous studies (gestational age at MR imaging and maternal body mass index (BMI) at early pregnancy ${ }^{17,18,26}$ ) as covariates. For the post hoc ROI comparisons, significances with and without controlling for all of these 5 covariates were both evaluated. For cohort 2, the TBSS and VBM analyses were performed without adding covari- 

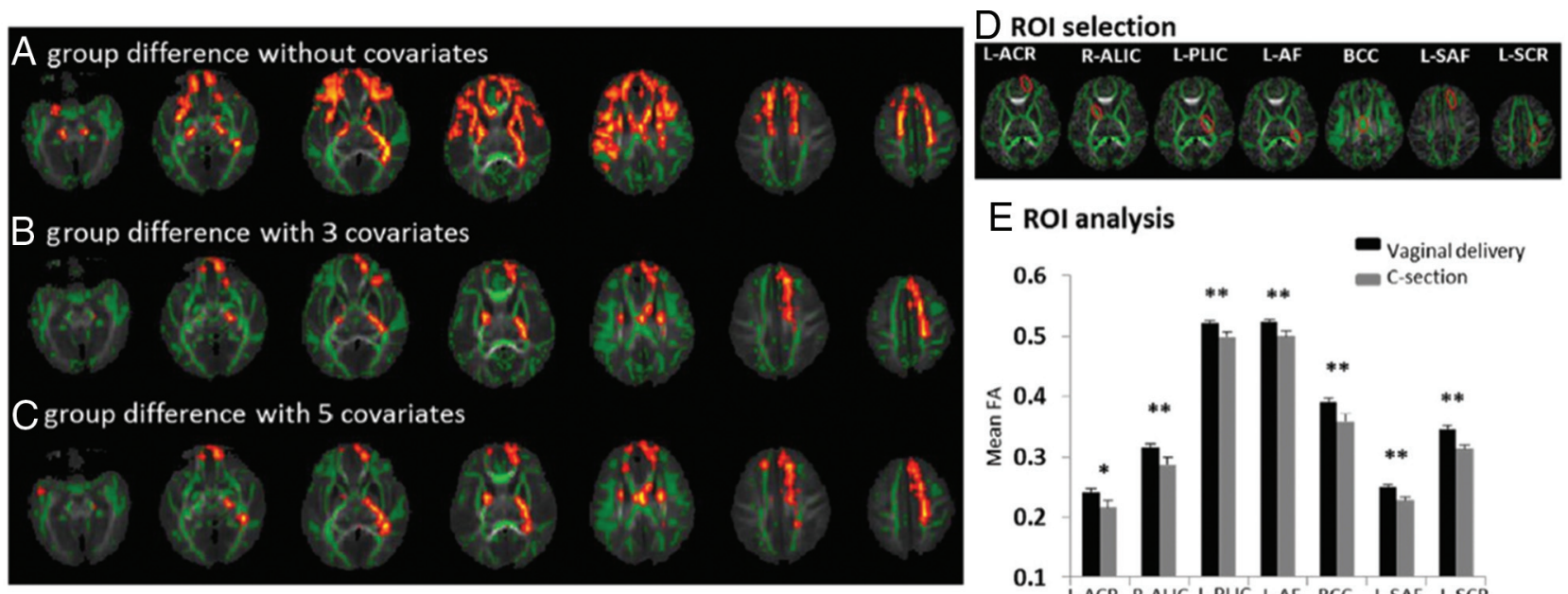

\section{E ROI analysis}

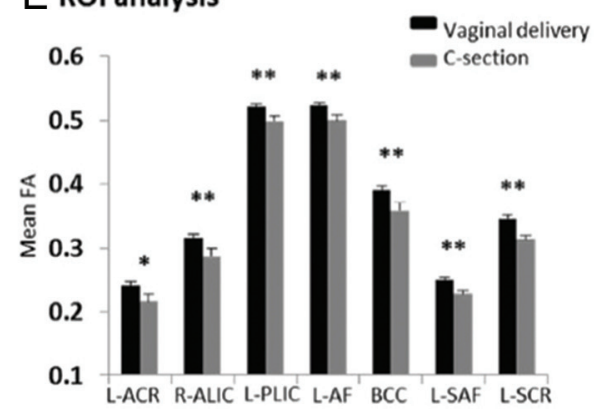

FIG 1. DTI TBSS results for the comparison of FA values between 2-week-old neonates born by cesarean delivery or vaginal delivery in cohort 1. Green represents major white matter tracts in the brain; orange shows voxels that have different FA values between groups. $A$, Group differences ( $P<.05$, corrected for the voxelwise multiple comparisons) when no covariates were added. $B$, Group differences $(P<.05$, corrected for the voxelwise multiple comparisons) when 3 demographic parameters that were different between groups (gestational weight gain, infant sex, and birth length) were added as covariates. $C$, Trend of group differences $(P<.15$, corrected for the voxelwise multiple comparisons) when an additional 2 potential confounders (gestational age at MR imaging and maternal BMI at early pregnancy) were included as covariates. D, Illustration of ROIs (red outlined) selected for further post hoc analysis. E, Group comparison of mean FA values in these white matter ROIs. L indicates left; R, right; ACR, anterior corona radiata; ALIC, anterior limb of internal capsule; PLIC, posterior limb of internal capsule; $\mathrm{AF}$, arcuate fasciculus; $\mathrm{BCC}$, body of the corpus callosum; SAF, short association fibers; $\mathrm{SCR}$, superior corona radiata; asterisk, $P<.05$ without controlling for covariates; double asterisks, $P<.05$ with and without controlling for covariates.

ates and then were repeated with age, sex, ${ }^{27}$ and infant $\operatorname{diet}^{22}$ added as covariates. Socioeconomic variables were not included as covariates because of incomplete data (group comparison on the available data did not show group differences other than mother's income).

\section{RESULTS}

The demographic/anthropometric/neuropsychological parameters are listed in Tables $1-3$ for the 3 cohorts. For cohort 1, the 2 groups of neonates did not differ with respect to mother's age, maternal IQ, and body fat percentage at early pregnancy, infant gestational age at MR imaging, birth weight, head circumference, and diet at 2 weeks of age. There was a trend toward differences in maternal BMI measured at 12 weeks of pregnancy (significant for the subjects included in the TBSS analysis but not significant for the subjects included in the RS-fMRI analysis). There were group differences in the mother's gestational weight gain, infant sex, and birth length. For cohort 2, the 2 groups of 8-year-old children did not differ in any demographic or family socioeconomic status measures except for mother's income. The neuropsychological test scores including IQ, language skills, and memory index were also not significantly different between groups. For cohort 3 , the 2 groups of children did not differ in birth weight, birth length, maternal education, number of scans per child, and mean interscan period. However, the cesarean delivery group had a higher maternal age and slightly lower gestational age at birth.

Imaging Findings for Cohort 1. DTI TBSS revealed widespread white matter regions in the frontal, parietal, and temporal lobes that had higher fractional anisotropy $(\mathrm{FA})$ values $(P<.05$, corrected for voxelwise multiple comparisons, indicating better white matter microstructural integrity and connectivity) in the vaginally delivered infants compared with those born by cesarean delivery (Fig $1 A$ ) when no covariates were added to the voxelwise analysis. Many of these differences were still significant $(P<.05$, corrected for voxelwise multiple comparisons) when the 3 demographic parameters that differed between groups (gestational weight gain, infant sex, and birth length) were added as covariates to the analysis (Fig 1B). Gestational age at MR imaging and maternal BMI at early pregnancy are potentially additional confounders influencing infant brain development. ${ }^{17,18,26}$ When they were also added as covariates into the analysis, the trend toward differences remained (at a level of $P<.15$ corrected for voxelwise multiple comparisons) for many clusters in this voxelwise analysis (Fig $1 C$ ) involving white matter tracts such as the anterior corona radiata, anterior/posterior internal capsule, arcuate fasciculus, short association fibers, superior corona radiata, and body of the corpus callosum. Further post hoc ROI analyses for these anatomic regions/white matter tracts (see Fig $1 D$ for an illustration of ROI selections) did show statistically significant differences in mean FA values between groups (Fig $1 E$ ), with a mean FA in infants born by vaginal delivery $4 \%-10 \%$ higher than that in infants born by cesarean delivery for different ROIs. For 6 of 7 ROIs, the differences in mean FA values were significant both with and without controlling for all covariates.

RS-fMRI analyses revealed functional connectivity differences between the 2 groups in the default mode network (DMN). Fig $2 \mathrm{~A}$ shows DMNs in neonates (obtained from the respective group ICA analyses), typical for the developing neonatal brain (that posterior regions such as posterior cingulate cortex and precuneus were well-recruited but anterior brain involvement was weak compared with that in older children). ${ }^{28}$ Dual-regression analysis for this ICA network showed a cluster in the precuneus region that had higher functional connectivity $(P<.05$, corrected for voxelwise multiple comparisons) in the vaginal delivery compared with 

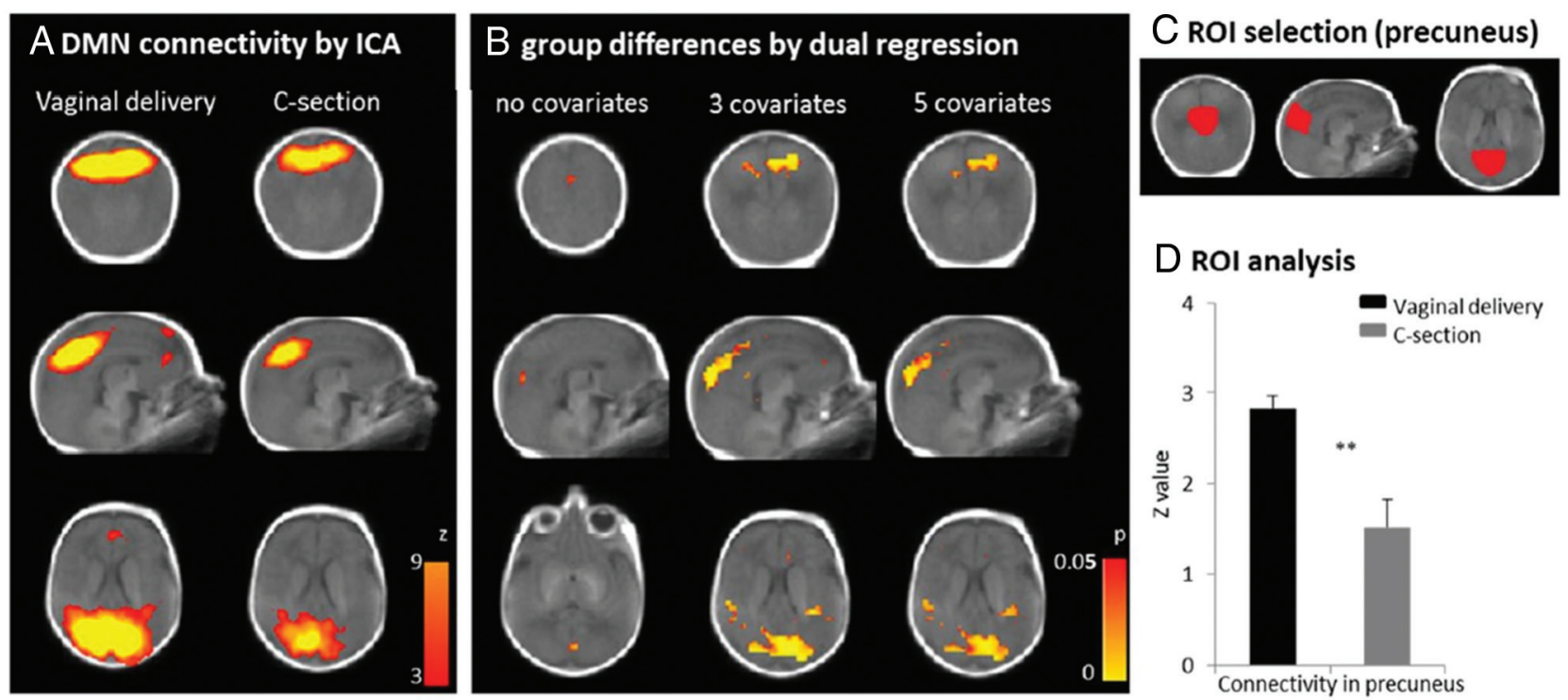

FIG 2. Resting-sate fMRI analyses of functional connectivity in the DMN in 2-week-old neonates in cohort 1. A, The DMN for vaginal and cesarean delivery groups obtained from respective independent component analysis (ICA). B, Regions in which the vaginal delivery group had higher functional connectivity ( $z$ score) in the DMN than the cesarean delivery group $(P<.05$, corrected for the voxelwise multiple comparisons) when excluding or including potential confounders as covariates. C, Illustration of ROI (precuneus selected) for further post hoc analysis. $D$, Comparison of the mean $z$ score values in the precuneus between the 2 groups. Double asterisks indicate $P<.05$ with and without controlling for covariates.

the cesarean delivery group (Fig 2B). After controlling for potential confounders (3 demographic parameters that differed between groups and 2 more parameters known to influence neonatal brain development), the differences were more prominent with a larger cluster in the precuneus and additional bilateral regions in the parietal lobes involved (Fig $2 B$ ). ROI analysis of mean $z$ scores in the precuneus (see Fig $2 C$ for an illustration of the ROI selection) confirmed lower functional connectivity $(P<.05$, with and without controlling for covariates) (Fig 2D). No other meaningful functional components obtained from the ICA showed significant group differences in the dual-regression analyses.

Imaging Findings for Cohort 2. DTI TBSS analysis did not show any clusters or imaging voxels with significant white matter FA value differences between children born by cesarean or vaginal delivery. Likewise, VBM did not show any clusters or imaging voxels with significant regional gray matter volume differences between groups. Excluding/including potential confounders (age, sex, infant diet) as covariates did not change the results.

Imaging Findings for Cohort 3. Significantly different brain developmental trajectories were observed for the 2 groups (Fig 3). Specifically, at $\sim 3$ months of age, the MWF for the infants born by vaginal delivery was higher (indicating better myelination) in the frontal, temporal, parietal, and occipital white matter and the body of corpus callosum compared with those born by cesarean delivery. The differences of MWF in white matter regions between groups were consistent during infancy but gradually decreased and were not observable at age $\sim 3$ years or beyond when the MWF for both groups reached the same plateau.

\section{DISCUSSION}

The imaging results from cohort 1 showed striking differences in brain structural connectivity (measured by DTI-TBSS) and func- tional connectivity (measured by RS-fMRI) in 2-week-old healthy neonates born by cesarean delivery compared with vaginal delivery, whereas measured imaging parameters (structural connectivity and brain volume) in 8-year-old healthy children in cohort 2 did not differ. These novel findings provide the first-ever evidence that cesarean delivery may be associated with a shift in brain development, at least during early infancy. Considering the potential importance of these findings and the post hoc nature of our analyses using data derived from a larger study, we sought confirmation in a separate cohort (cohort 3 ) in which imaging results from a different institution were evaluated with the investigator blinded to findings from cohorts 1 and 2 . The study in cohort 3 confirmed the delivery mode-associated differences in brain white matter development during infancy and was consistent in showing that differences dissipated with age. The differences in white matter development (as reflected by FA and MWF values) during infancy associated with delivery mode were widespread in both cohorts 1 and 3, involving the frontal, temporal, and parietal lobes and the corpus callosum, but not the cerebellum; the latter is one of the first regions to be myelinated, usually before birth. The differences were not prominent beyond age $\sim 3$ years, when myelination in most brain white matter regions approaches completion. Differences in resting-state functional connectivity were observed for the DMN network for neonates in cohort 1 , while at this age most brain functional networks are still being developed.

Birth mode-associated brain developmental differences were not observed in later childhood (ie, 8-year-old healthy children in cohort 2 and 5 -year-old healthy children in cohort 3 ). One possibility is that the differences were ameliorated during the years of postnatal development. Myelination for the cesarean delivery children may eventually catch up with that in children delivered vaginally when the developmental curve reaches a plateau after 
Corpus Callosum (Body)

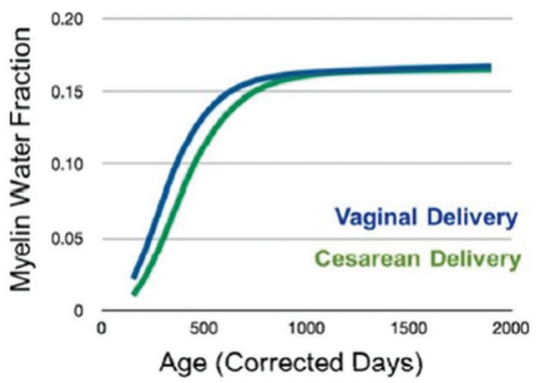

Frontal White Matter

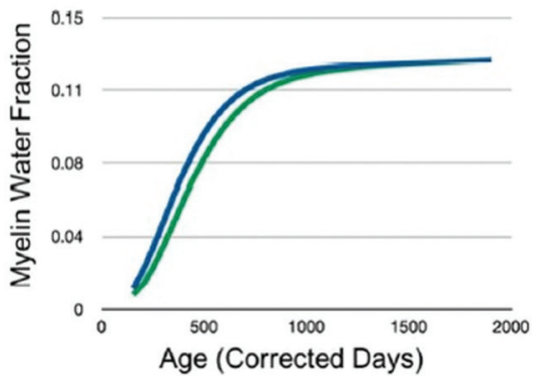

Cerebellar White Matter

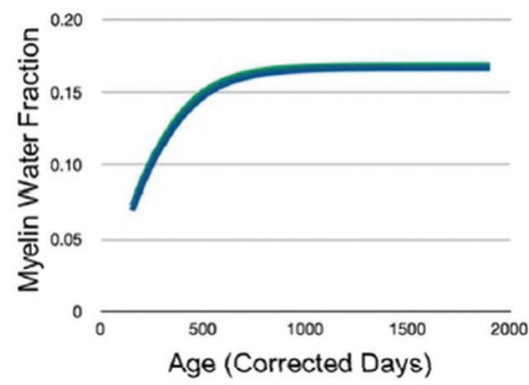

Temporal White Matter

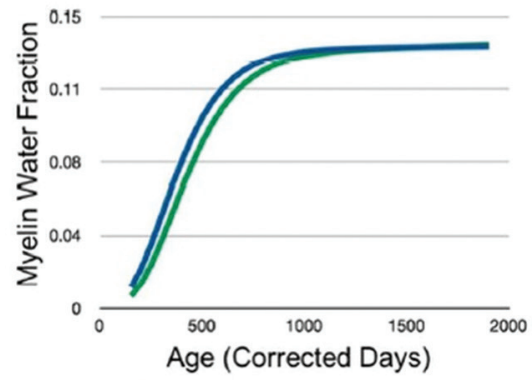

Occipital White Matter

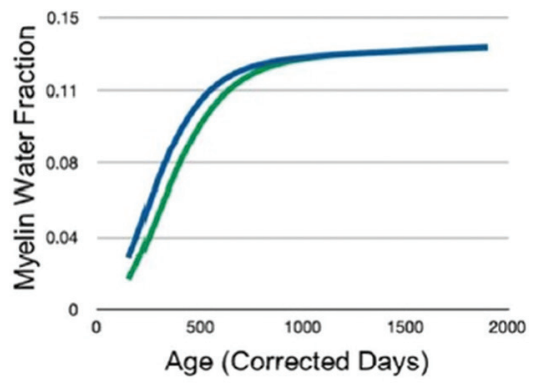

Parietal White Matter

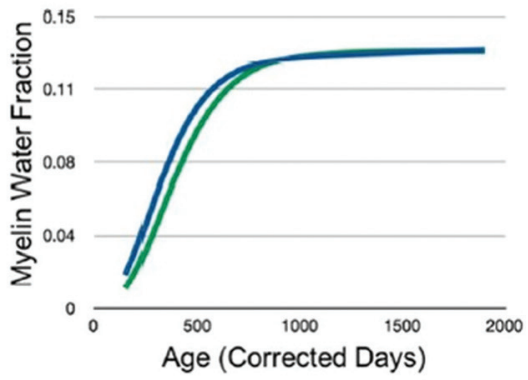

FIG 3. Longitudinal MWF in different brain regions for the vaginal delivery (blue) and cesarean delivery (green) groups in cohort 3. Children born by vaginal delivery had higher MWF (indicative of better white matter development) in most of the brain regions at young infancy, while the differences between groups gradually disappeared with age.

the first few years of life. In addition, breastfeeding (which reportedly promotes brain development in children ${ }^{20,22,29}$ ) may have driven enough changes to offset differences caused by cesarean delivery. Another possibility is the influence of the environment. While age, sex, and infant diet were included as covariates in cohort 2 and socioeconomic parameters were, in general, not different for the 2 groups in cohort 3 , extensive exposures to environmental factors (childhood diet, social enrichment, or other aspects) may have contributed to changes in neurodevelopment with long-term effects stronger than birth mode. For example, cognitive development in healthy children has been associated with breakfast consumption $^{30}$ and composition, ${ }^{31}$ physical activity, ${ }^{32}$ television-viewing time, ${ }^{33}$ and sleep duration. ${ }^{34}$ Many of these variables during childhood are difficult to quantify and were not considered in our study of older children. Recent population studies showed an increased risk of autism spectrum disorder and attention deficit/hyperactivity disorder associated with cesarean delivery that did not persist if using sibling controls ${ }^{11,35}$ and partially confirmed the confounding factors of family environment during childhood. In addition, while advanced and quantitative imaging methods were used in the evaluation of children's brain development in our study, it is possible that early brain structural differences associated with delivery mode introduced variations in brain function that could be apparent, for example, in the association of brain responses with stimulus-related information-processing.

The mechanisms underlying the effects of cesarean delivery on early life brain development are not known and could not be directly addressed in the current studies. Although cesarean delivery is generally considered a safe procedure, both mother and neonate are directly or indirectly subjected to factors that differ significantly from vaginal delivery, such as anesthesia/analgesics, surgical incisions, labor, trauma, stress, and so forth. It is not unreasonable to assume that these factors could have significant effects on the neonate's brain development. While speculative, we consider here a novel concept that associates cesarean delivery effects on neurodevelopment with an altered microbial environment. Several lines of evidence form the premise of this hypothesis. First, mode of delivery is a major determinant of gut microbiome composition in infants. ${ }^{36,37}$ Vaginally delivered neonates acquire bacterial communities resembling maternal vaginal microbiota, while cesarean delivery neonates have bacterial communities similar to those found on the skin surface, ${ }^{38}$ suggesting that the exposure to vaginal microbial environment during natural delivery is important for the initial establishment of neonate microbiota. Second, there is increasing evidence suggesting that gut microbiota modify central nervous system function and behavior, and microbiome-associated factors impact host immune activation, neural pathways, tryptophan metabolism and serotonin, gut hormone responses, and systemic exposures to bacterial metabolites. ${ }^{39}$ One or more of these events could, in theory, impact neurophysiology and development. A recent study of microbiota-deficient adult rodents showed differences in the regulation of genes linked to myelination and myelin plasticity in the prefrontal cortex, which was reversed by colonization with conventional microbiota. ${ }^{40}$ Third, a role for microglia and brain remodeling may be involved in response to the stressors and/or microbial-derived signals noted above.

One study in neonatal mice showed lower mitochondrial uncoupling protein 2 messenger RNA expression in the brain hippocampus associated with cesarean delivery. ${ }^{41}$ Uncoupling protein 2 expression during the early postnatal period is important for neuronal differen- 


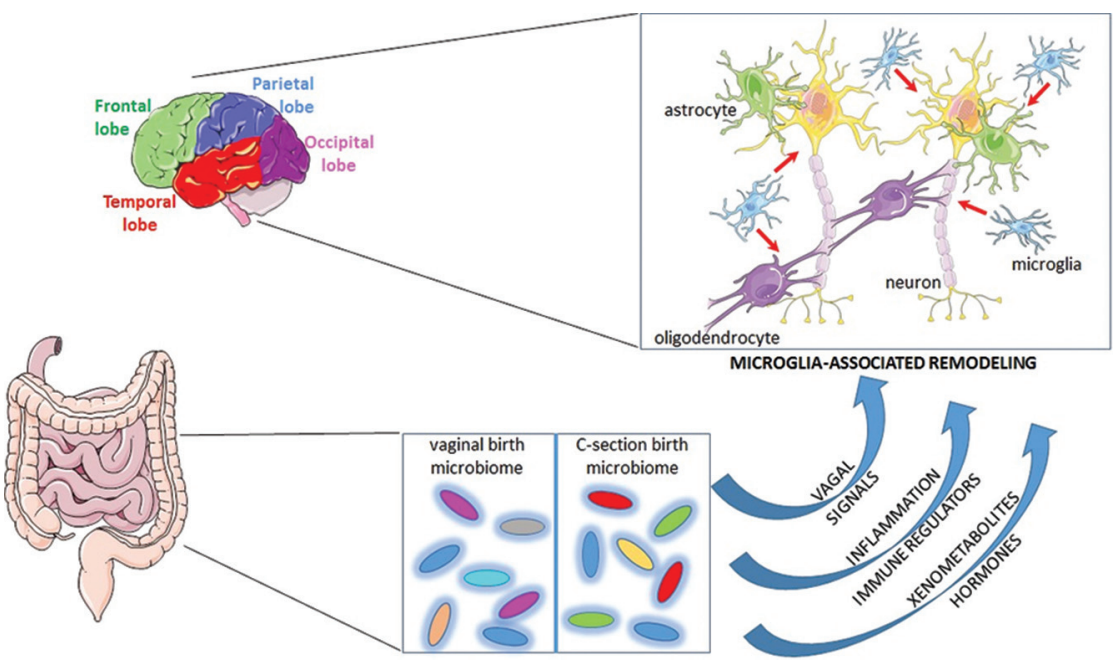

FIG 4. Illustration of a hypothetic model for mechanisms that drive differences in brains between infants with vaginal birth and cesarean delivery. Under this model, birth mode-associated changes to the gut microbiome lead to alterations in signals to the brain that regulate normal remodeling processes. Because microglia are implicated in this process, the model emphasizes this cell type as a major player in cell-cell cross-talk (red arrows) that modifies overall brain structure and function during the neonatal period. The model provides a theoretic framework for how birth mode contributes to normal neonatal brain development. The figure was generated, in part, by using components from the Servier Medical Art Powerpoint image bank (https://smart. servier.com/), which is under an open-use Creative Commons license.

tiation, axonal outgrowth, and synapse formation, ${ }^{42}$ and uncoupling protein 2 is highly expressed in microglia and important in microglia function. Most important, microglia are implicated in modifying neural circuits during early brain development. ${ }^{43}$ Thus, a working model is that cesarean delivery-associated changes in stress signals and/or the gut microbiome elicit a change in local signals of gut-brain cross-talk, in turn modifying brain microglia activities that impact brain development (Fig 4). Further study on animal models is necessary to evaluate this working model and explore the molecular mechanisms underlying cesarean delivery-associated changes in brain development and function.

There are several limitations in this study. First, it was based on secondary, post hoc analysis of MR imaging data for 3 cohorts, and the original study designs were not focused on detecting cesarean delivery effects on brain development. Second, because of age differences and institutional preferences, MR imaging methods were not the same for the 3 cohorts, and a complete characterization of the brain (ie, white/gray matter structure and function at rest and during tasks) for all subjects was not available. Nevertheless, the results from both institutions were consistent in illustrating brain developmental differences in infants and young children delivered by cesarean delivery that waned with age. Third, our results showed weakening delivery mode-associated differences on DTI measures after controlling for potential confounders. Gestational age, even for term pregnancy, and maternal BMI during pregnancy would also impact an infant's brain development, as shown by our previous publications. Nevertheless, the effects associated with cesarean delivery remained significant in cohort 1 after controlling for confounders for all measurements except the voxelwise TBSS. It is possible that there are additional confounders that may also interfere with the observation. In addition, reasons for cesarean delivery (eg, elective or emergent) and type of vaginal delivery (spontaneous or induced/instrument as- sisted) were not included as covariates because these parameters were not available for some subjects, and stratified analysis was not performed due to the limited sample size. Other factors during uncomplicated delivery, such as anesthesia use and length of labor, may also be potential confounders but were not considered. Despite limitations, this study provides the first evidence that cesarean delivery (which is usually complicated by multiple obstetric factors) may impact offspring's brain development. A prospective study specifically focused on this question, with a larger sample size, will be necessary to fully validate or refute this concept. Finally, our results were derived from healthy cohorts, so the association of delivery mode and brain development in compromised or at-risk infants could not be addressed. The strengths of our approach include statistical analyses considering relevant covariates and reproducibility in 2 independent cohorts at different sites.

\section{CONCLUSIONS}

Studies separately conducted at 2 independent institutions revealed significant effects of cesarean delivery on infant brain development, including reduced white matter microstructural integrity, weaker resting-state functional connectivity, and less myelination. While obstetric situations necessitating cesarean delivery not addressed in this study could also be potential confounding factors, these novel findings may have important clinical practice implications, given the increasing global prevalence of cesarean delivery. Nevertheless, there is no evidence from the current study that the effects are long-lasting at the brain anatomic level, considering that different structural measurements across age were used and functional connectivity were not assessed in the older cohorts. Additional studies are needed that look specifically at the impact of delivery mode on short- and long-term brain biology, neurocognition, learning, and behavior phenotypes.

\section{ACKNOWLEDGMENTS}

We thank the staff of the Arkansas Children's Nutrition Center Clinical Research Core, the Arkansas Children's Hospital Radiology MR imaging team, and the staff of the Advanced Baby Imaging Lab at Brown University for their assistance with these studies. We also thank Drs Aline Andres, Kartik Shankar, Mario Cleves, and Elisabet Borsheim for helpful discussion and/or reviewing this manuscript.

Disclosures: Sean C. Deoni-RELATED: National Institutes of Health, Comments: National Institute of Mental Health award as listed in the funding section*; UNRELATED: Consultancy: Nestlé Nutrition, Comments: consultant fees associated with nutritional impacts on neurodevelopment; Grants/Grants Pending: Nestlé Nutrition, Comments: study of nutritional impact on brain development*; Payment for Lectures Including Service on Speakers Bureaus: Wyeth Nutrition, Nestlé Nutrition, Comments: speaking fees for lectures on early brain development. Sean H. Adams- 
RELATED: Grant: US Department of Agriculture-Agricultural Research Service, Comments: The Arkansas Children's Nutrition Center is funded as a national research center by the US Department of Agriculture-Agricultural Research Service*; Support for Travel to Meetings for the Study or Other Purposes: US Department of Agriculture-Agricultural Research Service, Comments: The Arkansas Children's Nutrition Center is funded as a national research center by the US Department of Agriculture-Agricultural Research Service; the Center has travel support for its investigators to attend scientific conferences*; Provision of Writing Assistance, Medicines, Equipment, or Administrative Support: US Department of Agriculture-Agricultural Research Service, Comments: The Arkansas Children's Nutrition Center is funded as a national research center by the US Department of Agriculture-Agricultural Research Service. The Center has administrative support for its investigators*; UNRELATED: Consultancy: roundtable participant (eg, International Life Sciences Institute) and meeting organizer (eg, for the National Dairy Council); Employment: University of Arkansas for Medical Sciences; Grants/Grants Pending: US Department of Agriculture-Agricultural Research Service, Comments: The Arkansas Children's Nutrition Center is funded as a national research center by the US Department of Agriculture-Agricultural Research Service. This is not in conflict with the current article; Payment for Lectures Including Service on Speakers Bureaus, Comments: Various honoraria for invited seminars at universities or giving talks at national scientific conferences are not in conflict; topic areas have nothing to do with brain function or the subject matter of the current article; Travel/Accommodations/ Meeting Expenses Unrelated to Activities Listed: The Arkansas Children's Nutrition Center is funded as a national research center by the US Department of AgricultureAgricultural Research Service; the Center has travel support for its investigators to attend scientific conferences. * Thomas M. Badger-RELATED: Grant: National Institutes of Health and US Department of Agriculture*. Rudolph T. Pivik-RELATED: Grant: US Department of Agriculture-Agricultural Research Service Project 602651000-010-05S*; UNRELATED: Employment: University of Arkansas for Medical Sciences, Comments: only my salary as Research Professor, Department of Pediatrics. Charles M. Glasier-RELATED: Grant: Arkansas Children's Hospital; UNRELATED: Expert Testimony: medicolegal cases; Payment for Lectures Including Service on Speakers Bureaus: Cincinnati Children's Hospital. Amy C. Rowell-RELATED: Grant: US Department of Agriculture.* Xiawei Ou-RELATED: Grant: US Department of Agriculture-Agricultural Research Service Project 6026-51000-010-05S.* *Money paid to the institution.

\section{REFERENCES}

1. World Health Organization Human Reproduction Programme, 10 April 2015. WHO Statement on caesarean section rates. Reprod Health Matters 2015;23:149-50 CrossRef Medline

2. Martin JA, Hamilton BE, Osterman MJ, et al. Births: final data for 2013. Natl Vital Stat Rep 2015;64:1-65

3. Osterman MJ, Martin JA. Trends in low-risk cesarean delivery in the United States, 1990-2013. Natl Vital Stat Rep 2014;63:1-16

4. Cesarean delivery on maternal request. Committee Opinion No. 559. American College of Obstetricians and Gynecologists. Obstet Gynecol 2013:121;904-7.

5. National Institutes of Health state-of-the-science conference statement: cesarean delivery on maternal request March 27-29, 2006. Obstet Gynecol 2006;107:1386-97 CrossRef Medline

6. Barber EL, Lundsberg LS, Belanger K, et al. Indications contributing to the increasing cesarean delivery rate. Obstet Gynecol 2011;118: 29-38 CrossRef Medline

7. Kozhimannil KB, Law MR, Virnig BA. Cesarean delivery rates vary tenfold among US hospitals; reducing variation may address quality and cost issues. Health Aff (Millwood) 2013;32:527-35 CrossRef Medline

8. Hasab Allah MF, El Adawy AR, Moustafa MF, et al. Effect of mode of delivery on children intelligence quotient at pre-school age in ElMinia City. J Am Sci 2012;8:1188-98

9. Khadem $\mathrm{N}$, Khadivzadeh $\mathrm{T}$. The intelligence quotient of school aged children delivered by cesarean section and vaginal delivery. Iran J Nurs Midwifery Res 2010;15:135-40 Medline

10. Amiri S, Malek A, Sadegfard M, et al. Pregnancy-related maternal risk factors of attention-deficit hyperactivity disorder: a case-control study. ISRN Pediatr 2012;2012:458064 CrossRef Medline

11. Curran EA, Dalman C, Kearney PM, et al. Association between obstetric mode of delivery and autism spectrum disorder a population-based sibling design study. JAMA Psychiatry 2015;72:935-42 CrossRef Medline
12. Curran EA, O'Neill SM, Cryan JF, et al. Research review: birth by caesarean section and development of autism spectrum disorder and attention-deficit/hyperactivity disorder-a systematic review and meta-analysis. J Child Psychol Psychiatry 2015;56:500-08 CrossRef Medline

13. Talge NM, Allswede DM, Holzman C. Gestational age at term, delivery circumstance, and their association with childhood attention deficit hyperactivity disorder symptoms. Paediatr Perinat Epidemiol 2016;30:171-80 CrossRef Medline

14. Glasson EJ, Bower C, Petterson B, et al. Perinatal factors and the development of autism: a population study. Arch Gen Psychiatry 2004;61:618-27 CrossRef Medline

15. Chien LN, Lin HC, Shao YH, et al. Risk of autism associated with general anesthesia during cesarean delivery: a population-based birth-cohort analysis. J Autism Dev Disord 2015;45:932-42 CrossRef Medline

16. Dean DC 3rd, Jerskey BA, Chen KW, et al. Brain differences in infants at differential genetic risk for late-onset Alzheimer disease: a cross-sectional imaging study. JAMA Neurol 2014;71:11-22 CrossRef Medline

17. Li X, Andres A, Shankar K, et al. Differences in brain functional connectivity at resting-state in neonates born to healthy obese or normal-weight mothers. Int J Obes (Lond) 2016;40:1931-34 CrossRef Medline

18. Ou X, Thakali KM, Shankar K, et al. Maternal adiposity negatively influences infant brain white matter development. Obesity 2015;23: 1047-54 CrossRef Medline

19. Deoni SC, Dean DC, O'Muircheartaigh J, et al. Investigating white matter development in infancy and early childhood using myelin water faction and relaxation time mapping. Neuroimage 2012;63: 1038-53 CrossRef Medline

20. Ou X, Andres A, Cleves MA, et al. Sex specific association between infant diet and white matter integrity in 8-y-old children. Pediatr Res 2014;76:535-43 CrossRef Medline

21. Ou X, Andres A, Pivik RT, et al. Brain grey and white matter differences in healthy normal weight and obese children. J Magn Reson Imaging 2015;42:1205-13 CrossRef Medline

22. Ou X, Andres A, Pivik RT, et al. Voxel-based morphometry and fMRI revealed differences in brain gray matter in breastfed and milk formula-fed children. AJNR Am J Neuroradiol 2016;37:713-19 CrossRef Medline

23. Ou X, Glasier CM, Ramakrishnaiah RH, et al. Impaired white matter development in extremely low-birth-weight infants with previous brain hemorrhage. AJNR Am J Neuroradiol 2014;35:1983-89 CrossRef Medline

24. Smith SM, Jenkinson M, Johansen-Berg H, et al. Tract-based spatial statistics: voxelwise analysis of multi-subject diffusion data. $\mathrm{Neu}$ roimage 2006;31:1487-505 CrossRef Medline

25. Smith SM, Nichols TE. Threshold-free cluster enhancement: addressing problems of smoothing, threshold dependence and localisation in cluster inference. Neuroimage 2009;44:83-98 CrossRef Medline

26. Ou X, Glasier CM, Ramakrishnaiah RH, et al. Gestational age at birth and brain white matter development in term-born infants and children. AJNR Am J Neuroradiol 2017;38:2373-79 CrossRef Medline

27. Reiss AL, Abrams MT, Singer HS, et al. Brain development, gender and IQ in children: a volumetric imaging study. Brain 1996;119: 1763-74 CrossRef Medline

28. Gao W, Alcauter S, Smith JK, et al. Development of human brain cortical network architecture during infancy. Brain Struct Funct 2015;220:1173-86 CrossRef Medline

29. Deoni SC, Mercure E, Blasi A, et al. Mapping infant brain myelination with magnetic resonance imaging. J Neurosci 2011;31:784-91 CrossRef Medline

30. Liu JH, Hwang WT, Dickerman B, et al. Regular breakfast consumption is associated with increased IQ in kindergarten children. Early Hum Dev 2013;89:257-62 CrossRef Medline

31. Taki Y, Hashizume H, Sassa Y, et al. Breakfast staple types affect 
brain gray matter volume and cognitive function in healthy children. PLoS One 2010;5:e15213 CrossRef Medline

32. Sibley BA, Etnier JL. The relationship between physical activity and cognition in children: a meta-analysis. Pediatric Exercise Science 2003;15:243-56 CrossRef

33. Zimmerman FJ, Christakis DA. Children's television viewing and cognitive outcomes: a longitudinal analysis of national data. Arch Pediatr Adolesc Med 2005;159:619-25 CrossRef Medline

34. Dahl RE. The impact of inadequate sleep on children's daytime cognitive function. Semin Pediatr Neurol 1996;3:44-50 CrossRef Medline

35. Curran EA, Khashan AS, Dalman C, et al. Obstetric mode of delivery and attention-deficit/hyperactivity disorder: a sibling-matched study. Int J Epidemiol 2016;45:532-42 CrossRef Medline

36. Bäckhed F, Roswall J, Peng YQ, et al. Dynamics and stabilization of the human gut microbiome during the first year of life. Cell Host Microbe 2015;17:690-703 CrossRef Medline

37. Penders J, Thijs C, Vink C, et al. Factors influencing the composition of the intestinal microbiota in early infancy. Pediatrics 2006;118: 511-21 CrossRef Medline
38. Dominguez-Bello MG, Costello EK, Contreras M, et al. Delivery mode shapes the acquisition and structure of the initial microbiota across multiple body habitats in newborns. Proc Natl Acad Sci U S A 2010;107:11971-75 CrossRef Medline

39. Borre YE, O'Keeffe GW, Clarke G, et al. Microbiota and neurodevelopmental windows: implications for brain disorders. Trends $\mathrm{Mol}$ Med 2014;20:509-18 CrossRef Medline

40. Hoban AE, Stilling RM, Ryan FJ, et al. Regulation of prefrontal cortex myelination by the microbiota. Transl Psychiatry 2016;6:e774 CrossRef Medline

41. Simon-Areces J, Dietrich MO, Hermes G, et al. UCP2 induced by natural birth regulates neuronal differentiation of the hippocampus and related adult behavior. PLoS One 2012;7:e42911 CrossRef Medline

42. Seli E, Horvath TL. Natural birth-induced UCP2 in brain development. Rev Endocr Metab Disord 2013;14:347-50 CrossRef Medline

43. Tremblay MÈ, Stevens B, Sierra A, et al. The role of microglia in the healthy brain. J Neurosci 2011;31:16064-69 CrossRef Medline 